\title{
ÉTICA Y DETERMINISMO EN EL PENSAMIENTO DE GEORG LUKÁCS (Sobre la relación entre la sociedad y la literatura)
}

\author{
Sultana Wahnón
}

(Universidad de Granada)

He vendido mi alma dos veces al diablo, por monedas de niebla y curso clandestino en países que nadie se ha atrevido a fundar.

LUIS Garcfa MONTERO

1 LA PLURALIDAD ÉTICA EN EL PENSAMIENTO DEL JOVEN LUKÁCS

\subsection{El proyecto de una Sociología de las Formas}

Las primeras opiniones importantes de Lukács sobre la relación entre la literatura y la sociedad y sobre la disciplina que debía estudiar dicha relación se encuentran en el ensayo «La Forma dramática» (1909). En este temprano trabajo y en ese período de su producción 
intelectual que los estudiosos de Lukács, y Lukács mismo, ponen en relación con la fenomenología y el neokantismo (cfr. Parkinson, 1970: 11-12 y Ludz, 1961: 10-11), el filósofo húngaro, convencido de que las diferencias literarias serían «más profundas entre determinadas épocas que entre distintas individualidades de la misma época» (Lukács, 1909: 67), proclamaba ya su intención de estudiar la literatura desde un punto de vista sociológico, aunque cuidando de distanciarse de la sociología de la literatura que se practicaba por entonces y en la que veía dos importantes deficiencias. Lukács repudiaba en primer lugar su ambición por demostrar que las condiciones económicas de una época eran la causa inmediata del hecho artístico; y, en segundo lugar, su tendencia a localizar lo social del arte exclusivamente en los contenidos de las creaciones artísticas (1909: 67).

Frente a esa Sociología de la Literatura, que podríamos calificar de contenidista y mecanicista, el joven Lukács proponía una Sociología de la Literatura que se centrase en lo que, a su juicio, era «lo verdaderamente social de la Literatura», es decir, en la forma, y que, relegando las condiciones económicas a un papel subordinado e indirecto, estableciese relaciones directas entre las formas artísticas y «determinadas concepciones de la vida» - a las que, muy kantianamente, Lukács llamaba también «formas»- que se dan en «épocas determinadas». La Sociología de la literatura propuesta por el joven Lukács no debía -el teórico prefería decir que «no podía»- ocuparse de las causas (económicas) que originaban las diferentes concepciones de la vida correspondientes a épocas determinadas, pero sí debía y podía constatar el hecho de que «determinadas intuiciones del mundo aportan unas formas determinadas, las posibilitan, y del mismo modo excluyen otras a priori» (1909: 69). Cualquier cuestión estilística sería, por tanto y ante todo, una cuestión sociológica. Lo que Lukács venía a proponer, en consecuencia, era una sociología de la literatura muy emparentada, en sus métodos y fines, con la investigación estética que poco más tarde propondría Bajtin en su famoso ensayo «El problema del contenido, material y forma en la creación literaria» (1924). En 1914 Lukács expuso de manera muy parecida a como lo hizo Bajtin en este ensayo (cfr. Bajtin, 1924: 74) los objetivos de su primera sociología de la literatura:

«deseaba aclarar el problema central de una sociología de las formas literarias, esto es, llevar los elementos vitales temporales e históricos a una tipología formal, así como demostrar el aspecto formal en lo que comúnmente se llama el 'contenido' de las formas artísticas, para analizar a continuación las relaciones de cambio de ambos grupos de formas» (Lukács, 1914: 251). 


\subsection{La valoración ética en la composición del drama}

Lukács puso en práctica este programa metodológico sobre todo en dos trabajos: la Historia evolutiva del drama moderno (1912) y la Teoría de la novela que se publicó en 1920, pero que fue escrita entre 1914-15. En el primero, que fue su tesis doctoral, daba cuenta de las diferencias formales o estructurales entre el drama antiguo -entendiendo por tal el que va desde la Antigüedad al siglo XVII- y el drama moderno que habría comenzado con los ilustrados (Lessing, Schiller, etc.), para luego ponerlas en relación con diferencias entre las respectivas visiones, antigua y moderna, del mundo. En la construcción del drama moderno, por ejemplo, jugaría un papel importante lo que Lukács llama «la valoración», una nueva fuerza motriz de la composición dramática que no existía en el drama antiguo. La composición del drama antiguo estaría estrechamente relacionada con la visión del mundo propia de la nobleza, cuya seguridad ética - valorativahabría hecho que la acción dramática se organizase en torno a conflictos de carácter, pero nunca de valoración. Puesto que la valoración moral descansa, en estos dramas, sobre unas bases tan fuertemente metafísicas, tan poco susceptibles de relativización, la acción de un personaje contra ella sólo podía explicarse por situaciones psíquicas, pero no por razones teóricas: en el drama antiguo la «dialéctica dramática se encuentra en los caracteres» (Lukács, 1912: 269). Los personajes del drama antiguo no se ponen en movimiento ni colisionan entre sí por razones morales: la valoración ética no funciona como principio organizador de la acción. Los personajes del drama antiguo pueden obrar contra la moral - bien porque sean rufianes o bien porque estén dominados por pasiones demoníacas-, pero en todos ellos - justos o pecadores- el concepto y la valoración de lo moral son idénticos: «Por ello, Hegel pudo decir de manera justificada que las acciones shakesperianas no están 'moralmente justificadas'» (1912: 268).

El drama moderno sería, en cambio, una expresión de la burguesía, una clase que tuvo desde el primer momento conciencia de clase y que, por ello, jamás gozó de esa seguridad en sus propias valoraciones. Esta clase no pudo prescindir nunca «del hecho de que los sentimientos, pensamientos y valoraciones de los hombres cambiasen según las situaciones» (1912: 267). El drama burgués sería, pues, «el primero nacido de un contraste consciente de clases», lo que explicaría que en él tuviesen que salir a escena las diferentes clases en lucha, pero, sobre todo, que en él - y a diferencia de lo que ocurría en el drama anti- 
guo-, esas clases desempeñasen un papel decisivo en la estructura de la acción y de los caracteres de los dramas. De ahí la sensación de que el drama moderno posee «varios estratos frente al drama elaborado con un solo tema de todos los tiempos anteriores» (1912: 265). Así aparece en el drama moderno la nueva fuerza motriz de la valoración: lo que cada clase encarna en escena es una visión del mundo, una ideología. El mundo del nuevo drama se construye «sobre la base de diferentes éticas», y es la diferente visión del mundo de las clases la que «pone en movimiento a los hombres y los opone mutuamente» (1912: 267). Lukács llama a este rasgo estilístico o formal del drama moderno pluridimensionalidad en lo social.

En el análisis del carácter pluridimensional del drama moderno que Lukács realiza en este temprano trabajo podemos reconocer ya uno de los conceptos más característicos de su posterior estética marxista: el de la dialéctica forma-contenido. Pues lo que a primera vista se diría un problema del contenido - la existencia de diferentes valoraciones éticas en la sociedad burguesa-, se revela, iluminado por el joven Lukács, como un problema decisivo de la forma. En la consideración de la forma del drama moderno como plasmación estilística de una situación social nueva y de la nueva intuición del mundo que ésta genera, se cumple lo que Lukács formularía algunos años más tarde en los siguientes términos: «la aparición de una nueva temática produce una forma de leyes formales internas esencialmente nuevas, desde la composición hasta el lenguaje» (1934a: 38-39). Aun cuando todavía no era consciente de ello, Lukács ya estaba poniendo al descubierto la condición de reflejo de los elementos formales de la literatura.

En relación con este primer gran trabajo de Lukács, todavía cabría añadir algo: el carácter anticipador de sus tesis sobre la pluralidad valorativa del drama moderno en relación con las tesis de Bajtin. Este advertiría años más tarde, en una hipótesis tan conocida como contestada, que la pluralidad de conciencias en el drama no llegaba nunca a constituir un dialogismo porque, si bien «los personajes se enfrentan dialógicamente», lo harían «en el horizonte unificado del autor» que «resuelve todas las oposiciones dialógicas» presentando «un mundo unitario» (Bajtin, 1963: 32). Y, como anticipándose a la tesis del teórico ruso, cuya primera formulación dataría de 1929, Lukács advertía igualmente que, pese a la pluralidad de valoraciones que se enfrentarían en el drama moderno, «la valoración que constituye el fundamento del drama y pone en orden el mundo, es aún completamente unitaria y burguesa» (Lukács, 1912: 267). Si para Bajtin (1963: 32) el diálogo dramático estaría enmarcado en «un monólogo sólido e inexpugna- 
ble», para Lukács (1912: 267-68) lo estaría en lo que él llama una «'ética única' programática».

A pesar de su voluntad de no establecer relaciones mecánicas entre el arte y las condiciones económicas de una sociedad dada, Lukács creía en 1912 que las formas económicas de la clase burguesa dominaban «la vida entera» (Lukács, 1912: 272) y, por lo mismo, sí se permitió en este primer trabajo de sociología de la literatura establecer relaciones necesarias y mecánicas entre épocas, formas artísticas y clases sociales. Para el teórico húngaro, el drama moderno era inseparable de la burguesía: «El drama moderno es el drama de la burguesía; el drama moderno es el drama burgués» (1912: 252). Y, ahondando en el determinismo, añadía:

«cualquier drama es burgués, porque las formas de vida contemporáneas son burguesas y porque las formas de cualquier exteriorización de la vida actual están determinadas por sus formas» (1912: 272).

\subsection{La intención ética en la estructuración de la novela}

En su segundo y más importante trabajo, su famosa Teoría de la novela (1920), Lukács siguió relacionando formas artísticas y concepciones de la vida, pero no sin antes desposeer a su método de connotaciones sociologistas para acercarlo al de las «ciencias del espíritu» (cfr. Lukács, 1962: 15). Esto conlleva que en ningún momento de la obra se utilicen categorías sociológicas del tipo de «nobleza» o «burguesía». Las transformaciones en las formas artísticas se siguen correspondiendo con transformaciones en las visiones del mundo, pero estas últimas no se vinculan a las clases sociales en pugna, sino como mucho a las épocas históricas, concebidas ahora como épocas de la historia de la filosofía. Mientras que en el trabajo anterior se decía del drama antiguo que era el drama de la nobleza, en Teoría de la novela la epopeya será definida como la épica de las "civilizaciones cerradas», que es como llama Lukács a las culturas teológicas, es decir, a las civilizaciones de las épocas felices que creyeron en los dioses. En justa correspondencia, la novela no será definida en este trabajo concreto, a la manera hegeliana, como épica de la burguesía - aunque Lukács lo haría así en trabajos posteriores-, sino como épica de las «civilizacio- 
nes problemáticas», es decir, de las épocas sin dioses. Como ha señalado Parkinson, «la teoría lukacsiana de la novela no está tan arraigada en lo que él llamaría las condiciones históricas concretas como la de Hegel»; y parecería que en este período Lukács ve «la decadencia de la fe religiosa como teniendo lugar en un vacío social» (Parkinson, 1970: 14-15).

No es éste el único aspecto por el que el joven Lukács se aparta de Hegel en este trabajo sobre la novela, que habría sido definido por él mismo, sin embargo, como «la primera obra (...) que haya aplicado concretamente los resultados de la filosofía hegeliana a los problemas estéticos» (Lukács, 1962: 17). A pesar de que sea en este libro donde la crítica ha detectado «una fuerte influencia de Hegel» (Ludz, 1961: 11), sería erróneo considerarlo un trabajo de estricta observancia hegeliana. El capítulo titulado «El problema de la filosofía histórica de las formas» muestra claramente hasta qué punto ha abandonado Lukács una adhesión ingenua a la dialéctica hegeliana (cfr. Parkinson, 1970: 13). Ni siquiera es del todo cierto, aunque Lukács lo afirmara así en su severa autocrítica de este libro juvenil, que haya en Teoría de la novela una «historización de las categorías estéticas» heredada de Hegel (Lukács, 1962: 18). Una historia de las formas artísticas que hiciese «surgir cada forma de arte en el instante mismo en que, en el cuadrante del espíritu, se puede leer que su hora ha llegado» (Lukács, 1920: 40), erigiendo los géneros en símbolos - como ocurre en la estética hegeliana-, no es precisamente la historia del arte a la que aspira Lukács en este trabajo. Por el contrario, para el Lukács que, como él mismo advertirá más tarde, ha kierkegaardizado la dialéctica hegeliana (Lukács, 1962: 21), la coincidencia entre historia y filosofía de la historia sería posible sólo en las civilizaciones cerradas. Sólo en la historia del arte griego sería posible ver, clara y nítidamente, las formas del arte como símbolos en los que el sentido de la evolución histórico-filosófica se hace tangible: «Su historia del arte es una estética metafísicogenética; el desarrollo de su civilización una filosofía de la historia» (Lukács, 1920: 34). Las edades posteriores, en cambio, no conocerán ya esa periodicidad filosófica. Al igual que ocurría en la escena pluridimensional del drama moderno, en la civilización problemática descrita por Lukács en este trabajo coexistirían en simultaneidad una pluralidad de formas artísticas que traducirían una pluralidad de valoraciones éticas: «signos de búsquedas proponiéndose fines que dejan de estar dados de manera clara y unívoca» (1920: 40). Lukács advierte contra los intentos, que cree destinados al fracaso, de restaurar la unidad perdida del arte: «todo renacimiento del helenismo significa que la estéti- 
ca, más o menos conscientemente, se ha hipostasiado en pura metafísica» (1920: 37). Tanto la negativa a erigir los géneros en símbolos de épocas históricas como su explícito rechazo de una «estética metafísico-genética» (1920: 34) permiten hablar de un Lukács ajeno a la dialéctica y a la estética hegelianas y más próximo de lo que podría sospecharse a la tesis posmoderna del fin de la historia (para el concepto de dialéctica en Lukács, cfr. Mészáros, 1970).

En efecto, para el Lukács de la teoría de la novela, no habría un «sentido» inscrito en la evolución histórica. Las formas surgirían en ciertas condiciones histórico-filosóficas y el investigador podría lógicamente buscar y encontrar «las que presiden la aparición de cada forma singular» (1920: 40), pero no le sería lícito deducir de ahí ningún sentido, ni de progreso ni de decadencia, que le permitiese elaborar una filosofía de la historia: «No podemos ni queremos elaborar aquí ninguna filosofía de la historia (...); no vamos a determinar si es nuestro progreso o nuestra decadencia la que ha provocado esos cambios» (1920: 36). Para decirlo en términos actuales: Lukács trataría de dar cuenta de las transformaciones - del acaecer histórico-, pero no de legitimar la marcha de la humanidad - desde las civilizaciones cerradas a las problemáticas - con un metarrelato que viese en esa marcha un camino hacia la emancipación. En Teoría de la novela ya habría entrado en crisis la pacífica concepción lineal-unitaria del tiempo histórico y, con ella, todo el gran proyecto moderno-ilustrado.

Armado de este bagage post-metafísico, Lukács se propuso estudiar las condiciones histórico-filosóficas que presidieron la aparición de la novela. Sus tesis acerca de las relaciones entre epopeya y novela constituyen una primera formulación de la teoría lukacsiana de los géneros literarios. Para el joven Lukács, entre epopeya y novela no se habría producido un cambio de género. Cada género sería una manera de dar forma al universo que tendría sus leyes particulares de estructura y, por tanto, para que un género desaparezca y deje paso a otro nuevo, sería necesario que hubiera un cambio en «las disposiciones interiores del escritor» (1920: 55). Entre epopeya y novela no se habría producido un cambio de esta especie. Lo que habría cambiado sería solamente el principium stilisationis del género, por el que a la misma voluntad creadora, es decir, al mismo a priori corresponden, de modo necesario y «en virtud del condicionamiento histórico-filosófico», diversas formas de creación (1920: 39). Epopeya y novela serían, pues -en este caso, sí, coincidiendo con la estética de Hegel-, dos formas diferentes de un mismo género: la épica. Una misma disposición apriorística del espíritu - la épica- se orienta en la novela «hacia un fin nuevo, esen- 
cialmente distinto del viejo» (1920: 40). De modo que la dialéctica de los géneros del joven Lukács, como en general la de toda su producción, se caracteriza más por afirmar la vida histórica del género que por negar la existencia de ciertas estructuras genéricas invariables, que en el caso de Teoría de la novela son consideradas ahistóricamente como «formas intemporales ejemplares que corresponden a la estructuración del mundo» (1920: 34) (cfr. Wahnón, 1991: 135; y para una interpretación muy diferente de la teoría del género en Lukács, v. Garrido Gallardo, 1992: 24-25).

La épica sería una de esas formas intemporales y apriorísticas de estructuración, y su rasgo definitorio, el que la distingue de otros grandes géneros como el dramático, sería el de tener por objeto «la totalidad extensiva de la vida» (1920: 45). Pero, mientras que la epopeya formaría «una totalidad de vida acabada en sí misma», la novela buscaría «descubrir y edificar la totalidad secreta de la vida» (1920: 59). La causa de esta diferencia residiría en las diferentes condiciones histórico-filosóficas que se imponen al género: la epopeya sería la épica de los tiempos bienaventurados «que pueden leer en el cielo estrellado el mapa de los caminos» (1920: 29), mientras que la novela sería «la epopeya de un mundo sin dioses» (1920: 85 ).

Tal como se formula la diferencia, es fácil advertir que lo que Lukács llama aquí «condicionamiento histórico-filosófico» tiene mucho más que ver con condiciones filosófico-subjetivas que histórico-objetivas. Lo que habría cambiado entre las civilizaciones cerradas y la problemática no serían los datos de la realidad objetiva - «la parte de absurdo y de desolación en el mundo no ha aumentado desde el origen de los tiempos» (1920: 30)—, sino la forma subjetiva en que se percibe esa realidad. Si los antiguos no eran capaces de percibir esa parte de absurdo y desolación y veían el mundo más bien como «un todo acabado y cerrado» sostenido por los dioses, los individuos de la civilización problemática habrían dejado de percibir el mundo como dependiendo de voluntades sobrenaturales $y$, por tanto, habrían perdido el sentido de la totalidad, la visión de la realidad como una estructura cerrada e inmutable en su significación. No es extraño que Lukács defina el mundo de las civilizaciones cerradas como un círculo metafísico (1920: 33), ni que describa el efecto sobre el arte de la pérdida de la totalidad en términos similares a los utilizados por Nietzsche y después por Derrida:

«La realidad visionaria del mundo que nos es adecuada, el arte, por eso mismo se ha vuelto autónoma; ya no es copia, pues todo modelo ha desa- 
parecido; es totalidad creada, pues la unidad natural de las esferas metafísicas se ha roto para siempre» (1920: 36$)$.

La forma cerrada de la epopeya, su unidad orgánica, plasmaría, pues, una totalidad verdadera, es decir, percibida como realmente existente. La novela seguiría teniendo una forma cerrada, pero ésta, a diferencia de la de la epopeya, no descansaría en una unidad dada espontáneamente, sino que se trataría «de una tentativa desesperada, de una tentativa puramente artística» de reconstituirla por la vía de la composición (1920: 53). Para Lukács, es del todo obvio que esa totalidad que se trata de reconstituir no tiene una existencia objetiva: el todo de la vida no revela en sí ningún centro trascendental y no admite que una de sus células se arrogue el derecho de dominarlo (1920: 52). Es la intención ética la que estructura y construye la obra como si, «a pesar de todo», existiese una totalidad que reflejar (1920: 69). De ahí que mientras los héroes de la epopeya se limitan a buscar aventuras y vivirlas, los de la novela estén «siempre buscando» (1920: 59). La forma novelesca traduce, pues, la ausencia de una patria trascendental (1920: 60), pero también la nostalgia del alma que la añora y la busca «por el primer camino que parece conducirlo hacia ella» (1920: 84). La aspiración nostálgica de los hombres de la civilización problemática a un utópico acabamiento es la que explica que, a un mundo sin dioses y por tanto infinitamente abierto, corresponda una forma épica - la novelatodavía cerrada. No es casual que Lukács, anticipándose de nuevo a los teóricos más actuales, hable de clausura para referirse a este mundo novelesco en el que el cierre remite siempre a un gesto de «violencia» y a un sacrificio: el del «Paraíso por siempre perdido que hemos buscado y no hemos encontrado, cuya busca inútil y abandono designado han permitido cerrar el círculo de la forma» (1920: 82).

Para el Lukács desesperado del período bélico (cfr. Parkinson, 1970: 15), toda tentativa de clausurar la radical apertura del mundo sin dioses es, pues, una aspiración utópica que conlleva necesariamente un fracaso heroico. Se trataría de una utopía que permanecería inseparable de la «evidencia de que el fracaso es una consecuencia necesaria de su propia estructura interna» (Lukács, 1920: 113). Lukács se ve obligado, por tanto, a plantearse «el problema ético de la utopía», y lo hace en los siguientes, y posmodernos, términos:

«hasta qué punto se justifica moralmente el pensamiento de un mundo mejor, hasta qué punto está fundado edificar sobre esa base una vida que 
esté cerrada sobre sí misma y que no desemboque en un hueco mejor que en un fin» (1920: 112).

\subsection{Lukács y Dostoievski: la Teoría de la novela como precedente de la poética de Bajtin}

La respuesta a esta pregunta se encuentra en las páginas finales de Teoría de la novela, donde Lukács advierte que la tentativa por dar forma a lo utópico como si existiera «no lleva sino a destruir la forma y no a crear lo real» (1920: 147). La corrección que se impone a lo real para perfeccionarlo, la creación puramente artística de una realidad correspondiente a ese mundo soñado o, por lo menos, más adaptada a ese mundo que aquella que es efectivamente dada, no es, para Lukács, una solución. De ahí que el final de Teoría de la novela deba ser leído como una invitación de Lukács a abandonar lo que, siguiendo a Fichte, llama la «era de la perfecta culpabilidad» y, en consecuencia, a abandonar también la forma artística que le corresponde: la novela. Para Lukács, la novela habría llegado ya a un callejón sin salida, su evolución no habría «superado el tipo de la novela de la desilusión» y la literatura más reciente no revelaría "ninguna virtualidad esencialmente creadora, capaz de dar nacimiento a tipos nuevos» (1920: 146). Cuando Lukács le niega el carácter de «novelas» a las obras escritas por Dostoievski - en conclusión que, por ejemplo, Parkinson tiene por «gravemente errónea» (Parkinson, 1970: 14)-, no hace sino anticiparse una vez más al que es tenido por genial descubrimiento bajtiniano. Puesto que aquí se afirma que «la disposición interior» del «acto de estructuración» de las obras de Dostoievski no tiene ya nada que ver con la de la novela y puesto que esta última ha sido descrita en términos de violenta clausura de un mundo abierto, es evidente que Lukács está constatando no sólo la singularidad de la estructura novelesca de Dostoievski, sino también que esta singularidad reside en la ausencia de esa aspiración utópica - y culpable- al acabamiento:

«Con las obras de Dostoievski - dice Lukács confirmando esta impresión-, ese nuevo mundo se encuentra por primera vez definido lejos de toda oposición contra lo que existe, como pura y simple visión de la realidad» (1920: 147). 
Si bien es cierto que la Teoría de la novela rezuma la misma melancolía que en ella se denuncia como hija de la era de la perfecta culpabilidad, hay que advertir que al menos teóricamente Lukács no apuesta por esa nostalgia de totalidad. Lo ambiguo del lenguaje lukacsiano en este libro - el de mayores cualidades literarias de toda su producción- no puede ocultarnos que, para ser coherente con las tesis que en él ha expuesto, Lukács no podría ver en las novelas de Dostoievski el anuncio de una nueva civilización cerrada ni la restauración de la totalidad perdida. Es difícil imaginarlo reincidiendo en la misma «nostalgia decorativa» (1920: 112) que se ha ocupado de desenmascarar a lo largo de todo el trabajo, o abdicando de lo que él mismo había descrito como «la viril y madura comprobación de que jamás el sentido puede penetrar de lado a lado la realidad» (1920: 85). Las obras de Dostoievski debían de aparecérsele, eso sí, como hijas de una nueva era superadora de la «civilización problemática» que había dado origen a la forma artística de la novela, pero no porque volvieran a instaurar un círculo metafísico, sino porque en ellas se anunciaba una civilización abierta, que, a diferencia de la problemática, no se hacía problema ya de esa apertura. Las obras de Dostoievski serían, pues, las primeras que reflejarían fielmente ese mundo abierto, plural e inacabado que la estructura utópica de la novela - todavía con la resaca de la totalidad que se acababa de perder- se resistió a reflejar tal como era. Hay que convenir en que, a poco que hubiera leído las obras de Dostoievski - y debía de haberlas leído bien cuando se arriesgaba a aventurar la hipótesis de que no eran novelas-, tenía que haber intuido que el escritor ruso no era precisamente el profeta de un mundo cerrado y perfecto. Lukács sabía, por supuesto, que «sólo el análisis formal» de las obras de Dostoievski podría mostrar si éste era «ya el Homero o el Dante» de un «mundo nuevo» (1920: 147), y, aunque se ha especulado con la idea de que Teoría de la novela fuese la etapa previa de una monografía sobre Dostoievski (Ludz, 1961: 11, n. 19), fue Bajtin quien, lector y traductor de la Teoría de la novela de Lukács, habría de realizar ese análisis y concluir que, en efecto, las obras de Dostoievski habían destruido las formas establecidas de la novela europea (Bajtin, 1963: 18). Para entonces — de 1929 data la primera edición del trabajo bajtiniano- Lukács había encontrado otro camino hacia el nuevo mundo que no pasaba ya por la radical apertura de las obras de Dostoievski, sino por la acabada coherencia de las novelas de Balzac y de Tolstoi. 


\section{LA SOCIOLOGIA MARXISTA DE LUKACS CONTRA EL RELATIVISMO ÉTICO}

\subsection{La recuperación del concepto de totalidad}

Entre 1926 y 1933 Lukács abandonó prácticamente el trabajo teórico, limitándose a publicar algunas críticas en la revista de la Federación de Escritores Proletarios-Revolucionarios, Die Linkskurve (v. Lukács, 1931 y 1932). En 1934, tras este período de intensa actividad política, empezó a publicar los artículos de crítica y teoría literarias que tras el final de la guerra se integrarían en los libros más conocidos de la etapa marxista de Lukács. El «Lukács esencial» del que habla Steiner (1960: 330) se encuentra en libros como Goethe y su época (1947), El realismo ruso en la literatura universal (1949), Thomas Mann (1949), Realistas alemanes del siglo XIX (1951), Balzac y el realismo francés (1952), La novela histórica (1955). Y también en libros no relacionados con la literatura, pero imprescindibles para conocer la evolución del pensamiento marxista lukacsiano, como Historia y conciencia de clase (1923), Lenin (1924), El joven Hegel (1948) y El asalto a la razón (1954). En 1954 sus Aportaciones a la historia de la estética suponen el comienzo de una tarea, la de construir una estética marxista, que, concebida ya en el invierno de 1911-12 (v. Parkinson, 1970: 30), culminaría en Prolegómenos a una estética marxista (1957) y, sobre todo, en su monumental y algo farragosa Estética (1963) (v. para esta última obra Steiner, 1964).

La transición del joven Lukács al Lukács marxista está marcada por Historia y conciencia de clase, donde recuperó el concepto de dialéctica hegeliana $\mathrm{y}$, por consiguiente, volvió a captar la historia como un proceso unitario (Lukács, 1923: 57) cuya íntima significación no sería sino la del «desarrollo social» (1923: 53), es decir, la del progreso. La dialéctica permite, a su vez, que Lukács cambie de opinión respecto de la totalidad, la cual deja de ser vista como mera aspiración nostálgica de unos hombres abandonados de la mano de Dios para convertirse en la exacta y justa definición de la realidad socio-económica: «El conocimiento de los hechos no es posible como conocimiento de la realidad más que en ese contexto que articula los hechos individuales de la vida social en una totalidad» (1923: 53). Ese contexto es, lógicamente, el histórico: desvinculados de él, los hechos aparecen a ojos del observa- 
dor como aislados y faltos de significación; pero, en realidad, estarían comprendidos y perfectamente encajados en una unidad significativa que sería la del proceso total de la historia. Por eso, la sentencia de Marx acerca de que «las relaciones de producción de toda sociedad constituyen un todo" pasa a ser el punto de partida de la nueva metodología lukacsiana y «la clave misma del conocimiento histórico de las relaciones sociales» (1923: 54$)$.

Lo que ha hecho posible que la realidad vuelva a ser percibida como un todo, recuperando la unidad significativa que se perdió con la muerte de los dioses, es «la aparición del proletariado en la historia» (1923: 47). Esta clase social -con la que, en efecto, los trabajos anteriores de Lukács, centrados en el antagonismo entre nobleza y burguesía, entre antiguos y modernos, no habían contado- habría permitido «un conocimiento recto de la entera sociedad» (1923: 47). Desde la nueva perspectiva, inaugurada por el autoconocimiento del proletariado, la sociedad burguesa ya no es descrita como una sociedad abierta en la que un sinfín de puntos de vista sin legitimación metafísica se entrecruzan y sumen en la perplejidad a un individuo problemático, al que no le queda más remedio que aceptar la pluralidad como la única realidad posible. Ahora los diferentes puntos de vista son interpretados como contradicciones que pertenecen a «la esencia de la realidad misma, a la esencia de la sociedad capitalista» (1923: 55) y que no pueden dejar de ser descritas en una descripción de la sociedad capitalista que quiera ser justa y exacta. Ahora bien, el conocimiento de la totalidad no es sólo conocimiento de la totalidad concreta de la sociedad capitalista, sino, como ya se ha dicho, del proceso total de la historia; y, en este proceso, las contradicciones estarían llamadas a ser superadas, según lo muestran las «tendencias reales del proceso de desarrollo social» (1923: 55). Por esta razón, una descripción justa de la sociedad capitalista exige no sólo la descripción de las contradicciones que le son esenciales, sino también la descripción de las tendencias hacia su superación, que estarían encarnadas por el proletariado.

\subsection{La rectificación del concepto de necesidad histórica}

Estas ideas desempeñarían un importante papel en los análisis literarios que Lukács iba a realizar en su etapa marxista y en los que el énfasis se va desplazando al componente mimético o representativo de 
la literatura. Y no es que en esta etapa dejase por completo de cultivar la sociología de las formas literarias. Incluso los que juzgan más severamente a Lukács tienen que reconocer que siempre otorgó a la forma una «primacía que (...) lo separa radicalmente del 'contenidismo' de los marxistas vulgares» (Garrido Gallardo, 1992: 21). Sin embargo, la nueva orientación filosófica de Lukács introduce cambios notables en su consideración de las relaciones entre literatura y sociedad y, consecuentemente, en su sociología de la literatura.

Lukács no modifica en un punto su antigua y más característica convicción: la de que las formas literarias están determinadas por los contenidos o visiones del mundo. En la nueva etapa sigue pensando que cualquier cuestión estilística es una cuestión sociológica: «Toda composición poética se halla determinada de la manera más profunda, precisamente en sus principios estructurales, ideológicamente» (Lukács, 1936a: 201). Pero sí rectifica de manera ostensible todo lo que se refiere a la identidad que su anterior sociología establecía entre épocas y formas. Aun cuando reconoce que cada nuevo estilo surgiría «con necesidad social-histórica de la vida» y sería «el producto necesario de la evolución social» (1936a: 180), ni por un casual se le ocurriría ahora sostener, como sostuvo antes, que la vida contemporánea entera estaría dominada por las formas de vida - y de arte- burguesas. Ni todo drama ni, especialmente, toda novela tendrían por qué ser necesariamente burgueses a pesar de producirse en una sociedad burguesa. Sin desaparecer de la nueva sociología lukacsiana, el concepto de «necesidad histórica» sufre, por tanto, una corrección importante: no habría necesidades verdaderamente vinculantes $y$, por tanto, no habría una sola forma artística para cada época histórica.

De ahí que la nueva propuesta de Lukács sea la de una sociología de la literatura que, convirtiéndose en estética, asuma como tarea propia la valoración estética de las diferentes formas artísticas, ya que «el reconocimiento de (...) la necesidad del origen de los estilos artísticos, dista mucho todavía de hacer a estos estilos artísticamente equivalentes o de igual rango", puesto que la necesidad "puede también ser una necesidad hacia lo artísticamente falso, deformado y malo» (Lukács, 1936a: 180). La principal preocupación del Lukács marxista es, por tanto, la de distanciarse de una sociología, a la que califica de vulgar, que se conforma con describir el llamado equivalente de los diversos escritores o estilos porque «cree que con la demostración de la historia social del origen toda cuestión se halla contestada y liquidada» (1936a: 181) y que, de esta guisa, acaba por relativizar sociológicamente las formas artísticas y borrando «la diferencia objetiva entre alto arte y 
chapucería» (Lukács, 1934a: 42). Ahora no bastaría, como bastaba en Teoría de la novela, con buscar y encontrar las condiciones históricas que presiden la aparición de cada forma singular: la tarea de la ciencia de la literatura no puede consistir meramente, a juicio del Lukács marxista, en descubrir el equivalente social de Homero o de Joyce y en declarar que ambos son "productos» de su época y su sociedad (Lukács, 1936a: 181). La renovada sociología lukacsiana se propone, pues, como tarea inexcusable la de la valoración:

«Comprender la necesidad social de un estilo determinado no es lo mismo que valorar estéticamente las consecuencias artísticas de dicho estilo. En estética no rige el lema: 'Comprenderlo todo significa perdonarlo todo'» (1936a: 181).

\subsection{La valoración de las formas novelescas: Narración y Totalidad}

Uno de los dos textos que venimos citando para ilustrar las objeciones puestas por Lukács a la sociología vulgar, el titulado « ¿Narrar o describir? A propósito de la discusión sobre naturalismo y formalismo» (1936a), ejemplifica además el nuevo método de análisis sociológico de las formas literarias propugnado por Lukács. Ya desde el título, se oponen dos estilos como excluyentes y obligan al sociólogo que ejerce su misión valorativa a optar por uno de ellos. En el caso concreto que nos ocupa, se trata de dos modos de escribir novela -el género al que en la etapa marxista va a dedicar Lukács la mayor parte de sus esfuerzos. La elección de uno u otro por parte de los novelistas contemporáneos estaría determinada por «su actitud fundamental frente a la vida, frente a los grandes problemas de la sociedad» (1936a: 177). Pero Lukács no entiende ya estas diferencias como signos de legítimas búsquedas en un mundo sin dioses en el que los fines no son ya ni claros ni unívocos. En el universo maniqueo de estos textos marxistas, como en los salones del Oeste americano, dos no caben, y uno de los dos - desempeñando el papel del malo de la película - tiene que plasmar por fuerza una «concepción fundamental equivocada de la realidad, del ser objetivo de la sociedad» (1936a: 182). La «equivocación» en el contenido se traduce necesariamente en una forma artística equivocada o, si se prefiere, falsa; y esta deformación se interpreta siempre, en el período de la producción lukacsiana que estamos analizando, como un alejamiento de la esencia del 
género al que las obras en cuestión pertenecen. En el artículo «Arte y verdad objetiva» Lukács lo formula así de claro: «todo género tiene sus leyes objetivas determinadas de plasmación que ningún artista, so pena de la destrucción de su obra, puede pasar por alto» (Lukács, 1934a: 38-39).

En el caso concreto que nos ocupa, el estilo culpable sería la descripción. No porque la descripción no haya sido siempre un componente importante de la plasmación épica, sino porque lo habría sido como medio subordinado y no, como ocurriría en las obras de algunos novelistas contemporáneos, como "principio decisivo de la composición» (Lukács, 1936a: 177). Para Lukács, el predominio de la descripción sobre la narración en las novelas de Flaubert, Zola, Joyce o Dos Passos estaría cambiando la misión de la descripción en la composición épica y, por tanto, alterando profundamente las leyes del género. Esto no tendría mayor gravedad, si no fuera porque una alteración de esta especie impide al arte épico cumplir el que, para Lukács, es ahora el principal de sus objetivos: el reflejo justo y profundo de la realidad objetiva, que, para serlo, tiene que ser reflejo de la vida en movimiento, de las «fuerzas impulsoras de la evolución social» (1936a: 183). Limitándose a la observación exterior y superficial de los síntomas de la vida burguesa, Flaubert, por ejemplo, sería incapaz de captar esas fuerzas, y la vida en sus novelas aparecería «como un río que corre uniformemente, como una superficie lisa y monótona, sin articulación» (1936a: 182). Algo parecido ocurriría en la obra de Zola, a quien los «prejuicios triviales de la sociología burguesa» le llevan igualmente a plasmar la vida «casi sin articulación» (1936a: 183).

El reflejo correcto de la realidad objetiva está, para Lukács, vinculado al predominio de la narración sobre los elementos descriptivos: «La narración articula, la descripción nivela» (1936a: 187). Balzac y Tolstoi se convierten en autores ejemplares porque, al dar predominio a la narración, traducen la concepción dialéctica de la realidad, ya que, al igual que ella, la narración articula los elementos aislados en un todo (1936a: 187). La forma de la novela modélica - portadora de la concepción dialéctica del proletariado- es ahora, en consecuencia, la misma que, según el Lukács de la Teoría de la novela, plasmaba, por el contrario, la ética burguesa y su afán, siempre condenado al fracaso, de clausurar la apertura del mundo. Cuando Lukács, en el ensayo de 1936, invita a hacer de nuevo de la narración el principio decisivo de la composición, no está sino instando a escribir novelas que, como las que él mismo describió en Teoría de la novela, busquen descubrir y edificar la totalidad secreta de la vida, o que, como dice ahora, des- 
pierten «la ilusión de la plasmación de la vida entera en toda su extensión completamente desplegada» (1936a: 188).

Pero ¿se trata sólo de una ilusión o del reflejo justo de la totalidad real y objetiva? En este punto los textos lukacsianos abundan en contradicciones. Por un lado, ya se ha dicho que para el Lukács marxista la totalidad es objetiva y realmente existente -como proceso total de la historia y como totalidad socio-económica concreta. Por tanto, no tiene nada de particular que Lukács inste a los escritores - haciendo del arte de nuevo una «copia» de la realidad-a descubrir, por debajo de las apariencias fenoménicas, de la superficie de la sociedad capitalista, esa totalidad realmente existente aunque velada a miradas superficiales:

«Debido a la estructura objetiva de este sistema económico, la superficie del capitalismo se presenta como 'desgarrada', consta de elementos que se independizan de modo objetivamente necesario. (...) La independización de los elementos parciales es, por consiguiente, un hecho objetivo de la economía capitalista. Sin embargo, sólo forma una parte, un solo momento del proceso conjunto. Y la unidad, la totalidad, la coherencia objetiva de todas las partes, pese a la independización objetivamente existente y necesaria, se manifiesta precisamente en la crisis» (Lukács, 1938a: 292).

Por otro lado, sin embargo, parecería que Lukács sigue apuntando, como en Teoría de la novela, a que la cohesión significativa de la obra literaria es algo construido artísticamente. En «Arte y verdad objetiva» es ésta la hipótesis que se maneja. Lukács insiste aquí en que, si no quiere traicionar sus leyes más objetivas de plasmación, toda obra literaria tiene que «presentar una cohesión coherente, redondeada, acabada, y tal, además, que sus movimientos y estructura resulten directamente evidentes» (Lukács, 1934a: 20). Pero insiste igualmente en que ninguna obra podría proponerse reflejar la totalidad objetiva y extensiva de la vida, la cual iría «necesariamente más allá del marco posible de toda creación artística» (1934a: 23). Se trataría más bien de que, mediante la selección por parte del artista de las determinaciones objetivas esenciales que delimitan la porción de vida por ella plasmada, la obra aparezca «cual una totalidad de la vida» (1934a: 23). De ahí que, en la obra modélica diseñada por Lukács, el final desempeñe un papel de primera importancia: «Forma parte de la esencia de su construcción y de su efecto el que solamente el final proporcione la aclaración verdadera y completa del principio» (1934a: 20). Como especificaría en otro lugar, el sentido de la complicada concatenación de las acciones humanas sólo puede abarcarse con la mirada desde el final, y el épico 
que «narra retrospectivamente, a partir del final, (...) hace clara y comprensible para el lector la selección de lo esencial efectuada por la vida misma» (Lukács, 1936a: 188). Es obvio que Lukács, sin decirlo con estas palabras, apuesta decididamente por clausurar el texto y que no ve ya en ello ningún signo de nostalgia ni de violencia significativa:

«el lector es conducido a través del entrelazamiento de motivos de enlaces variados por el autor omnisciente, que conoce el significado particular de cada detalle, en sí mismo insignificante, en relación con el desenlace final y con la revelación definitiva de los caracteres» (1936a: 189).

Entre las muchas polémicas que sostuvo Lukács con otros teóricos marxistas - de las cuales la más conocida es la polémica con Brecht-, se contó la que lo enfrentó a Ernst Bloch precisamente en relación con el concepto de «totalidad» y las consecuencias artísticas del mismo que se acaban de exponer. Bloch veía en la descripción de la realidad objetiva por parte de Lukács como realidad íntegramente coherente un mero residuo de los sistemas del idealismo clásico; y entendía que su aversión a los sistemas compositivos de la novela más contemporánea provenía de «un concepto objetivista-unitario de la realidad» que se volvía «contra todo intento artístico orientado a descomponer un concepto del universo»:

«De ahí que, en un arte que aprovecha las desintegraciones de la trabazón de la superficie y trata de descubrir algo nuevo en las cavidades, él no vea más también que descomposición subjetivista; de ahí que equipare el experimento del descomponer al estado de la descomposición" (cit. por Lukács, 1938a: 290-91).

Lukács se defendió de estos reproches insistiendo en que la sociedad burguesa constituía «en la realidad, objetiva e independientemente de la conciencia, un todo" (1938a: 291) y en que, siendo la literatura una forma particular del reflejo de la realidad objetiva, los escritores tenían que «captar esta realidad tal como es efectivamente, y no limitarse a reproducir lo que directamente parece» (1938a: 293). La polémica fue, pues, un diálogo entre sordos, pero lo más interesante de la misma reside seguramente en que Lukács atribuye a su Teoría de la novela parte de responsabilidad en lo que consideraba el «error histórico de Bloch» (1938a: 302). Lukács era, pues, consciente de que en esta obra «juvenil», y a despecho de la opinión actualmente generalizada sobre ella, no había apostado por ninguna suerte de totalidades. 
En cambio, es evidente que en la etapa marxista sí lo hace. Por esta razón, si en Teoría de la novela se hacían votos para que la novela, como género que traduciría una melancólica y esteticista aspiración utópica, desapareciese - acompañando en su caída a la era de la perfecta culpabilidad que la había generado-, ahora, en todas las obras del Lukács marxista, se hacen votos para que la novela, como género que traduciría las leyes esenciales del gran arte épico, no desaparezca nunca y, por tanto, no arrastre consigo a la civilización racional e ilustrada a la que habría servido de expresión. De cuánto tuvo que ver en estos cambios la nefasta experiencia del advenimiento y triunfo del fascismo en Europa no puede hablarse aquí, pero conviene no olvidar que los intentos desesperados de Lukács por salvar lo mejor de la civilización burguesa, incluidas sus novelas decimonónicas, obedecieron en gran parte al comprensible terror pánico que le inspiraron las nuevas formas de civilización que se anunciaban en la década de los treinta.

Sea como fuere, y volviendo a la caracterización de la nueva sociología valorativa de Lukács, lo que Lukács llamaba «valoración estética» era algo muy parecido a una valoración ética o ideológica. En el análisis sociológico de las formas literarias lo que se juzga — como se ha visto en el caso de la descripción - es la actitud ante la vida del escritor en cuestión, aunque el error en ésta implique, a causa de la dialéctica forma-contenido, un paralelo error en la forma. El propio Lukács habría reconocido que en su etapa marxista el contenido se convierte en «el elemento preponderante del análisis y el juicio» (Lukács, 1965: 10). Si esto es así - como se ha visto- incluso en aquellos casos en que el objeto de análisis es el estilo, mucho más lo será en los casos que ilustran lo que Steiner considera «lo esencial de la práctica lukácsiana», es decir, «el estudio minucioso de un texto literario a la luz de las cuestiones políticas y filosóficas» (Steiner, 1960: 334).

\subsection{La valoración de los contenidos: la cuestión del realismo}

En estos trabajos, que son los típicamente «contenidistas» de la sociología lukacsiana, se trata de valorar los textos literarios atendiendo a su grado de correspondencia con la objetividad del mundo exterior reflejado. Es importante advertir que la captación de la realidad no está reñida, en la teoría lukacsiana, con la ideología. Como diría en 
otro lugar, «sin ideología no existe composición alguna» (Lukács, 1936a: 202). La de Goethe, cuando escribe el Werther, por ejemplo, no es sino la del humanismo revolucionario burgués. Pero Goethe ilustraría el lema engelsiano de la «victoria del realismo», según el cual en las grandes obras literarias el escritor se desprende de la visión del mundo a que estaría supuestamente determinado por su origen social e histórico para darnos una visión objetiva de la realidad (v. Lukács, 1938b: 81). El triunfo de la plasmación realista sobre los prejuicios individuales y de clase de un escritor es, para Lukács, el resultado de «la fecunda relación recíproca de los escritores importantes con la realidad» (íbid.). Y en el caso de Goethe esa fecunda relación se daría, pues su entusiasta adscripción a los ideales del humanismo revolucionario no le habría impedido ver, en la «vida cotidiana de su época» (Lukács, 1936b: 75), a fuerza de profunda observación —que no de miradas superficiales-, la trágica contradicción de esos ideales, todo lo que en el propio ideario burgués se opondría al «despliegue libre y omnilateral de la personalidad humana» (1936b: 75). Su ideología no le habría impedido, por tanto, expresar la dialéctica real de la evolución de la sociedad burguesa. Naturalmente, el joven Goethe carece de la comprensión económica de los hechos que observa, y será el crítico -en este caso Lukács- el que nos ofrezca la explicación en última instancia económica de las contradicciones del humanismo burgués:

«La división capitalista del trabajo - base sobre la cual puede por fin proceder la evolución de las fuerzas productivas que posibilita materialmente el despliegue de la personalidad-somete al mismo tiempo al hombre, fragmenta su personalidad encajonándola en un especialismo sin vida, etc.» (1936b: 76).

Puesto que Goethe escribe en un momento muy temprano de la evolución de la sociedad burguesa, Lukács no le va a exigir, a la hora de concederle la calificación de realista, más que la plasmación de las contradicciones que, según se veía arriba, pertenecen a la esencia de esta sociedad. Lo mismo ocurre con otros grandes escritores del realismo burgués, como Walter Scott, Balzac y Tolstoi. Si las novelas históricas de Scott le parecen la mejor expresión del género es porque el método de plasmación histórica y humana con que Scott da vida a la historia es el que consiste en presentar la historia como «un proceso lleno de contradicciones, un proceso cuya fuerza motriz y base material es la contradicción viva de las potencias históricas en pugna» (Lukács, 1955b: 58). Y también la «grandeza» de Balzac residiría en 
que sabe observar y configurar con ojos insobornables todas las contradicciones manifiestas (Lukács, 1934b: 323).

Cuando se trata del análisis de escritores contemporáneos, la metodología del análisis de contenido es la misma; pero en estos casos la fiel representación de las contradicciones ideológicas no es la única condición que exige Lukács - sobre todo en la etapa del realismo socialista - para hablar de un «triunfo del realismo». Desde su temprano artículo sobre las novelas de Willi Bredel, publicado en Die Linkskurve, Lukács dejó claro que una visión correcta y profunda, dialéctica, de la realidad histórico-social presente no era sólo la que representaba la realidad histórica como proceso contradictorio y lleno de dificultades, sino también la que la representaba, a pesar de las dificultades, en claro avance hacia la claridad ideológica, configurando «la línea ascendente del movimiento revolucionario» (Lukács, 1931: 301). En otras palabras: $E \mathrm{El}$ socialismo realista se propone como misión fundamental la plasmación del devenir y el desarrollo del hombre nuevo» (Lukács, 1934a: 53).

En este sentido hay que entender los reproches que dirigió a escritores como Flaubert y Zola. Su debilidad ideológica decisiva radica, para Lukács, en que capitulan sin lucha «ante las manifestaciones acabadas de la realidad capitalista" (1936a: 206), representando ciertamente la inhumanidad del sistema capitalista, pero sin tener en cuenta que «vive también en la sociedad burguesa el proletariado» (1936a: 205). A la inversa, no hay que olvidar que Lukács dirigió también duros reproches a los escritores socialistas que, queriendo representar la línea ascendente del proletariado, concedían una fácil victoria al hombre nuevo y se olvidaban igualmente de representar las contradicciones del proceso histórico. Lukács les acusaba igualmente de falta de realismo. En el caso concreto de Willi Bredel, Lukács - coherente con la concepción de la sociedad y de la historia que defendió en Historia y conciencia de clase - hablaba de una deficiencia de dialéctica que acababa falsificando el cuadro en su contenido (Lukács, 1931: 300). Bredel, urgido por la exigencia de representar el advenimiento del hombre nuevo, no describía en sus novelas el proceso histórico con todas sus contradicciones y dificultades, sino que presentaba directamente la sociedad que se deseaba resultante del proceso obviado:

«El decente apolítico se hace 'repentinamente' comunista; la célula mal preparada 'de repente' se hace cargo de la dirección de la huelga; en las reuniones siempre vence la línea revolucionaria contra los caciques, etc.» (1931: 301). 
A diferencia del héroe problemático de Teoría de la novela, incapaz de percibir «esa otra voz que sin equívoco le mostraría el camino a seguir, el fin hacia el cual debe tender» (Lukács, 1920: 83), el nuevo héroe lukacsiano está bañado en la misma atmósfera de seguridad que los héroes de la antigua epopeya, pues, aunque no sepa cómo llegar y ya sea que encuentre al término del viaje el resplandor del desastre o el estallido del triunfo, sí sabe al menos hacia dónde se dirige. Pero, al igual que los héroes de la epopeya, debe tropezar con obstáculos y dificultades en ese camino trazado de antemano. Y Bredel no describía en sus obras «cuán difícil resulta para las masas el camino que deben recorrer para alcanzar la claridad ideológica» (Lukács, 1931: 301). Aun cuando la superación de las contradicciones fuese el objetivo final al que tendía el autoconocimiento del proletariado, Lukács no animó nunca a hacer del arte un instrumento propagandístico que presentase de forma anticipada en la ficción lo que en la realidad todavía no existía. Su defensa del realismo fue, en este sentido, enormemente consecuente y nunca pudo servir de apoyo a la política de lo que se conoce como realismo socialista (para el enfrentamiento de Lukács con las tesis de Zdanov, v. Benassi, 1989: 75-76).

Para concluir, Lukács no fue sólo un sociólogo de la literatura. A la idea de la determinación social de las obras literarias contrapuso él, a partir del momento en que observó los efectos del relativismo sociológico sobre la praxis humana —el debilitamiento del juicio moral y la consiguiente parálisis de la acción-, la idea de que era posible escapar a las determinaciones históricas y sociológicas y defender formas y contenidos supuestamente anacrónicos y sentenciados a muerte por el implacable progreso occidental. En esta resistencia a dejarse llevar por los vientos de la historia residió seguramente la grandeza de Lukács. Héroe problemático él mismo, nunca esquivó los tormentos de la búsqueda ni los peligros del descubrimiento. La preferencia por el Lukács sociólogo o el Lukács marxista ha respondido, a lo largo de la segunda mitad del siglo XX, a las orientaciones dominantes en el horizonte crítico. En los años sesenta y setenta el Lukács marxista era de lectura obligada e inspiró a teóricos tan importantes como Lucien Goldmann. En las postrimerías del siglo la ética posmoderna contenida en su Teoría de la novela, que fue tenida en esos años por obra idealista y reaccionaria, puede aparecerse como una digna precursora del horizonte postestructuralista. 


\section{Referencias bibliográficas}

BATJín, M. (1924). «El problema del contenido, el material y la forma en la creación literaria». En Teoría y estética de la novela (1975). Madrid: Taurus, 1989.

- (1963). Problemas de la poética de Dostoievski. México: F.C.E., 1986.

Benassi, S. (1989). «Sociologia della letteratura. Temi e analisi». En Teoria del Romanzo. Tra letteratura e filosofia, Bologna, Nuova Alfa, En Teoria..., 65-89. Bologna: Nuova Alfa.

Garrido Gallardo, M. A. (1992). La teoría literaria de György Lukács, Valencia: Amós Belinchón.

LuDz, Peter (1961). «Prólogo». En Lukács, 1961: 5-61.

LUKÁCS, G. (1909). «Del prólogo a Historia evolutiva del drama moderno». En Lukács, 1961: 67-70.

- (1912). «Sociología del drama moderno». En Lukács, 1961: 251-81.

- (1914). «Advertencia preliminar» a Lukács, 1912.

- (1920). Teoria de la novela. Buenos Aires: Siglo XX, 1966.

- (1923). Historia y conciencia de clase. Barcelona: Orbis, 1985 (reprod. de la ed. de Grijalbo, 1969).

- (1931). «Las novelas de Willi Bredel». En Lukács, 1961: 297-302.

- (1932). «¿Reportaje o configuración? Observaciones críticas con ocasión de la novela de Ottwalt». En Lukács, 1961: 119-38.

- (1934a). «Arte y verdad objetiva». En Lukács, 1955a: 11-54.

- (1934b). «Balzac: Los campesinos». En Lukács, 1961: 313-30.

- (1936a). « ¿Narrar o describir? A propósito de la discusión sobre naturalismo y formalismo». En Lukács, 1955a: 171-216.

- (1936b). «Los sufrimientos del joven Werther». En Lukács, 1947: 69-89.

- (1938a). «Se trata del realismo». En Lukács, 1955a: 288-318.

- (1938b). «Marx y la decadencia ideológica». En Lukács, 1955a: 55-110.

- (1955a). Problemas del realismo. México: F.C.E., 1966.

- (1955b). La novela histórica. México: Era, 1966.

- (1961). Sociología de la literatura. Barcelona: Península, 1966. Selec. y ed. P. Ludz.

- (1962). «Prólogo» a Teoría de la novela (V. Lukács, 1920: 13-26).

- (1965). «Prólogo a la edición española» de Problemas del realismo (V. Lukács, 1955a).

Meszaros, I. (1970). «El concepto de dialéctica en Lukács». En Parkinson, 1970: 45-102.

Parkinson, G.H.R. (ed., 1970). Georg Lukács. El hombre, su obra, sus ideas. Barcelona: Grijalbo, 1973.

STEINER, G. (1960). «Georg Lukács y su pacto con el diablo». En Lenguaje y silencio (1976), 323-40. México: Gedisa, 1990.

- (1964). «Un manifiesto estético». En Lenguaje y silencio, 341-49.

WAHNÓN BENSUSAN, S. (1991). Introducción a la historia de las teorías literarias. Granada: Universidad de Granada. 